\title{
Simultaneous quantification of phenolic acids and flavonoids in Chamaerops humilis L. using LC-ESI-MS/MS
}

\author{
Aicha BOUHAFSOUN ${ }^{1 *}$, Mustafa Abdullah YILMAZ ${ }^{2,3}$, Ahmed BOUKELOUA ${ }^{4}$, Hamdi TEMEL ${ }^{3}$, \\ Meriem KAID HARCHE ${ }^{1}$
}

\begin{abstract}
In this study, heated reflux extraction method has been used to identify the phenolic compounds from C. humilis var. argentea leaflets, rachis and fruits. Extractions were performed in both ultrapure water and $80 \%$ methanol solvents. The efficiency of procedures was determined in terms of the quality and quantity of phenolic acids and flavonoids identified. Chamaerops extracts have been characterized by high concentrations of phenolic compounds, which play a crucial role in protection against various diseases. LC-MS/MS was used to determine the chemical profile of various extracts obtained from Chamaerops. The results showed that the major components in leaflets and fruits extracts were quinic, malic and chlorogenic acids. In addition, nine minor acidic components were identified. On the other hand, rutin and hesperidin were found to be the major flavonoids. The methanol extract was shown as being the most efficient to identify phenolic compounds in C. humilis.
\end{abstract}

Keywords: Chamaerops humilis L.; LC-ESI-MS/MS; phenolic compounds; chemical composition; extracts.

Practical Application: Chamaerops humilis L. rich in flavonoids and phenolic acids was a great promising source of different bioactive components.

\section{Introduction}

Flavonoids and phenolic acids, a class of polyphenol compounds, are widely distributed in plants kingdom. Flavonoids include over 6000 identified family members. They play an important role in protection of plants from microbial and insect attack. Many studies reported that flavonoids exhibit various effects as antioxidant (Siahpoosh et al., 2016; Balci \& Özdemir, 2016), anti-cancer (Androutsopoulos et al., 2010; Ma et al., 2015), anti-allergic (Park et al., 2006), anti-thrombotic and vasodilatory (Rahimi et al., 2010), anticholinesterase (Ertas et al., 2016) actions. Finally, because of their UV-absorbing properties, flavonoids protect plants from the UV radiation of the sun and scavenge UV-generated reactive oxygen species (Shirley, 1996).

Chamaerops humilis L., var. argentea, belonging to the Arecaceae family, is a palm widely distributed in the Mediterranean basin especially in Algeria which has been located mainly in Tlemcen and Oranian coast. In folk medicine, this plant has been widely applied by decoction in Algerian populations for a variety of illnesses as stomachache, toning (Hasnaoui et al., 2011), diabetes (Bnouham et al., 2002). Moreover, previous studies reported Chamaerops to contain phenolic compounds, such as tannins, flavonoids, saponins, quinons, coumarines (Benahmed-Bouhafsoun et al., 2013), sterols and terpenoids (Hasnaoui et al., 2013).
Additionally, antioxidant (Benahmed-Bouhafsoun et al., 2013; Khoudali et al., 2014), hypoglycemic and hypolipidemic (Gaamoussi et al., 2010), antilithic (Beghalia et al., 2008), anti-inflammatory and urinary antiseptic (Bellakhdar et al., 1991) activities of $C$. humilis were reported.

The flavonoids were previously reported as constituents of the Arecaceae family plants, but literature lacks detailed information on the phytochemical composition of C. humilis. This is the first study for the identification and quantification of phenolic acids and flavonoids of $C$. humilis. Therefore, the objective of the present study was to characterize the chemical composition of water and $80 \%$ methanol extracts of $C$. humilis leaflets, rachis and fruits by using liquid chromatography coupled with mass spectrometry (LC-ESI-MS/MS) as a potent analytical technique.

\section{Materials and methods}

\subsection{Chemicals and instruments}

The phenolic identification and quantification of $C$. humilis were determined by using LC-ESI-MS/MS (Shimadzu, Kyoto, Japan). (L)-Malic acid (purity: 95-100\%), quercetin (95\%), protocatechuic acid (97\%), chrysin (97\%), rutin (94\%), hesperetin (95\%), naringenin (95\%), rosmarinic acid (96\%), vanillin (99\%),

${ }^{1}$ Laboratoire de Production et Valorisation Végétale et Microbienne, Département de Biotechnologie, Faculté des Sciences de la Nature et de la Vie, Université des Sciences et de la Technologie d'Oran Mohamed Boudiaf - USTO-MB, Oran, Algérie

${ }^{2}$ Dicle University Science and Technology Research and Application Center - DUBTAM, Dicle University, Diyarbakir, Turkey

${ }^{3}$ Department of Pharmaceutical Chemistry, Faculty of Pharmacy, Dicle University, Diyarbakir, Turkey

${ }^{4}$ Département de Biologie, Faculté des Sciences Exactes et Sciences de la Nature et de la Vie, Université d’Oum El Bouaghi, Oum Bouaghi, Algérie

*Corresponding author: abouhafsoun@gmail.com 
p-coumaric acid (98\%), caffeic acid (98\%), chlorogenic acid (95\%), hyperoside ( $\geq 97 \%)$, myricetin ( $\geq 96 \%)$, coumarin ( $\geq 99 \%$ ), kaempferol ( $\geq 97 \%$ ) were obtained from Sigma (Germany); quinic acid (98\%), tr-aconitic acid (98\%), 4-hydroxybenzoic acid ( $\geq 99 \%)$, fisetin ( $\geq 98 \%$ ) were from Aldrich (Germany); gallic acid ( $\geq 99 \%)$, tannic acid (puris), salicylic acid ( $\geq 99 \%$ ) were from Sigma-Aldrich (Germany); hesperidin ( $\geq 97 \%)$, luteolin ( $\geq 97 \%)$, apigenin $(\geq 99 \%)$, rhamnetin ( $\geq 99 \%)$ were from Fluka (Germany). HPLC grade methanol was purchesed from Merck, USA.

\subsection{Plant material}

Chamaerops humilis L. Var. argentea was collected by Dr. A. Bouhafsoun from western Algeria (Oran city) in June of 2014 .

\subsection{Extraction under continuous reflux}

Three grams of dried samples were soaked separately in $50 \mathrm{ml}$ of $80 \%$ aqueous methanol and ultrapure water at $60^{\circ} \mathrm{C}$ for $30 \mathrm{~min}$. The extracts were filtered through nylon filter. The extraction was repeated twice. The collected filtrates were dried under vacuum using a rotary evaporator at $30^{\circ} \mathrm{C}$ until dry extracts were obtained. Dry filtrates were diluted to $1000 \mathrm{mg} / \mathrm{L}$ and filtrated with $0.2 \mu \mathrm{m}$ microfiber filter prior to LC-MS/MS analysis.

\subsection{LC-MS/MS instrumentation and chromatographic conditions}

LC-MS/MS analysis of the phenolic compounds was performed by using a Nexera model Shimadzu UHPLC coupled to a tandem MS instrument. The liquid chromatography was equipped with LC-30AD binary pumps, DGU-20A3R degasser, CTO-10ASvp column oven and SIL-30AC autosampler. The chromatographic separation was performed on a C18 reversed-phase Inertsil ODS-4 (150 mm $\times 4.6 \mathrm{~mm}, 3 \mu \mathrm{m})$ analytical column. The column temperature was fixed at $40{ }^{\circ} \mathrm{C}$. The elution gradient consisted of mobile phase A (water, $5 \mathrm{mM}$ ammonium formate and $0.1 \%$ formic acid) and mobile phase $\mathrm{B}$ (methanol, $5 \mathrm{mM}$ ammonium formate and $0.1 \%$ formic acid). The gradient program with the following proportions of solvent $\mathrm{B}$ was applied $\mathrm{t}(\mathrm{min}), \mathrm{B} \%$ : $(0,40),(20,90),(23.99,90),(24,40),(29,40)$. The solvent flow rate was maintained at $0.5 \mathrm{~mL} / \mathrm{min}$ and injection volume was settled as $4 \mu \mathrm{L}$.

\subsection{MS instrumentation}

MS detection was performed using Shimadzu LCMS 8040 model triple quadrupole mass spectrometer equipped with an ESI source operating in both positive and negative ionization modes. LC-MS/MS data were collected and processed by LabSolutions software (Shimadzu, Kyoto, Japan). The multiple reaction monitoring (MRM) mode was used to quantify the analytes: the assay of investigated compounds was performed following two or three transitions per compound, the first one for quantitative purposes and the second and/or the third one for confirmation. The optimum ESI conditions were determined as interface temperature; $350^{\circ} \mathrm{C}, \mathrm{DL}$ temperature; $250^{\circ} \mathrm{C}$, heat block temperature; $400{ }^{\circ} \mathrm{C}$, nebulizing gas flow (nitrogen); $3 \mathrm{~L} / \mathrm{min}$ and drying gas flow (nitrogen); $15 \mathrm{~L} / \mathrm{min}$.

\subsection{Method validation parameters}

In this study, twenty-four phenolic compounds (flavonoids, flavonoid glycosides, phenolic acids, phenolic aldehyde, coumarin) and three non-phenolic organic acids that are widespread in edible plant materials were qualified and quantified in two edible plants. Rectilinear regression equations and the linearity ranges of the studied standard compounds were given in Table 1. Correlation coefficients were found to be higher than 0.99. The limit of detection (LOD) and limit of quantitation (LOQ) of the reported analytical method were shown in Table 1. For the studied compounds, LOD ranged from 0.05 to $25.8 \mu \mathrm{g} / \mathrm{L}$ and LOQ ranged from 0.17 to $85.9 \mu \mathrm{g} / \mathrm{L}$ (Table 1) (Ertas et al., 2015). Moreover, the recoveries of the phenolic compounds ranged from $96.9 \%$ to $106.2 \%$.

\subsection{Statistical analysis}

All experiments were conducted in triplicate and the data was presented as the mean value \pm standard deviation (SD).

\section{Results and discussion}

In this study, twenty seven compounds (authentic markers) were studied for their dominant fragmentation pathways (Figure 1).

Most of the compounds in MS exhibited abundant [M - H] - in negative ion mode and $[\mathrm{M}+\mathrm{H}]+$ in the positive ion mode were subjected to MS/MS analysis, retention time (RT) and mass spectral characteristics of all marker compounds were given in Table 1.

The variables considered during reflux extraction process including $80 \%$ methanol and ultrapure water were tested for the extraction of polyphenols from rachis, leaflets and fruits of Chamaerops, in order to achieve high extraction efficiency of phenolic acids and flavonoids. After LC-MS/MS analysis,

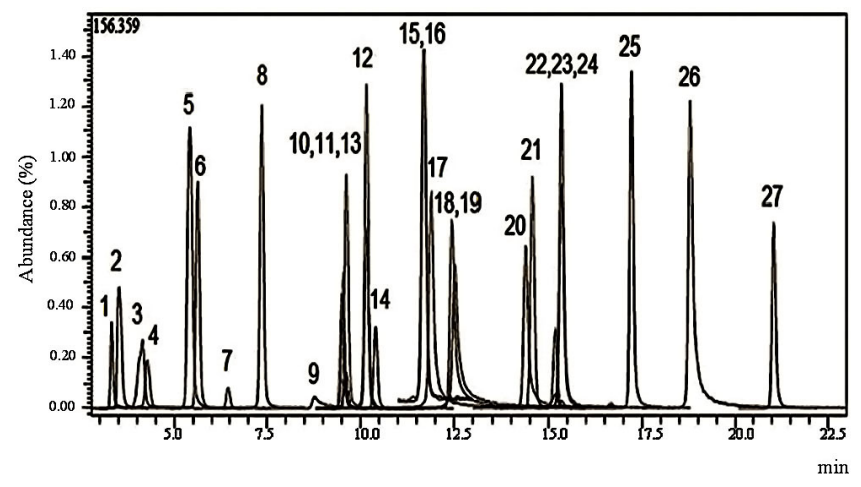

Figure 1. Total Ion Chromatogram (TIC) of $250 \mathrm{ppb}$ standard mix. 1: Quinic acid, 2: Malic acid, 3: tr-Aconitic acid, 4: Gallic acid, 5: Chlorogenic acid, 6: Protocatechuic acid, 7: Tannic acid, 8: tr-caffeic acid, 9: Vanillin, 10: $p$-Coumaric acid, 11: Rosmarinic acid, 12: Rutin, 13: Hesperidin, 14: Hyperoside, 15: 4-OH Benzoic acid, 16: Salicylic acid, 17: Myricetin, 18: Fisetin, 19: Coumarin, 20: Quercetin, 21: Naringenin, 22: Hesperetin, 23: Luteolin, 24: Kaempferol, 25: Apigenin, 26: Rhamnetin, 27: Chrysin. 
Table 1. Analytical parameters of LC-MS/MS method.

\begin{tabular}{|c|c|c|c|c|c|c|c|c|c|c|}
\hline No & Analytes & $\mathrm{RT}^{\mathrm{a}}$ & $\mathrm{r}^{2 \mathrm{~b}}$ & $\begin{array}{l}\text { Ion. } \\
\text { Mode }^{c}\end{array}$ & Equation & $\mathrm{RSD} \%{ }^{\mathrm{d}}$ & $\begin{array}{c}\text { Linearity } \\
(\mathrm{mg} / \mathrm{L})\end{array}$ & $\begin{array}{c}\mathrm{LOD} / \mathrm{LOQ} \\
(\mu \mathrm{g} / \mathrm{L})^{\mathrm{e}}\end{array}$ & $\begin{array}{c}\text { Recovery } \\
(\%)\end{array}$ & $U^{f}$ \\
\hline 1 & Quinic acid & 3.36 & 0.9927 & Neg & $f(x)=25133+33.6 x$ & 0.0388 & $250-10000$ & $22.3 / 74.5$ & 103.3 & 4.8 \\
\hline 2 & Malic acid & 3.60 & 0.9975 & Neg & $f(x)=-5674+93.6 x$ & 0.1214 & $250-10000$ & $19.2 / 64.1$ & 101.4 & 5.3 \\
\hline 3 & tr-Aconitic acid & 4.13 & 0.9933 & Neg & $f(x)=-28416+79.3 x$ & 0.3908 & $250-10000$ & $15.6 / 51.9$ & 102.8 & 4.9 \\
\hline 4 & Gallic acid & 4.25 & 0.9901 & Neg & $f(x)=26417+358.1 x$ & 0.4734 & $25-1000$ & $4.8 / 15.9$ & 102.3 & 5.1 \\
\hline 5 & Chlorogenic acid & 5.29 & 0.9932 & $\mathrm{Neg}$ & $f(x)=26780+49.0 x$ & 0.1882 & $250-10000$ & $7.3 / 24.3$ & 99.7 & 4.9 \\
\hline 6 & Protocatechuic acid & 5.51 & 0.9991 & Neg & $f(x)=6197+36.9 x$ & 0.5958 & $100-4000$ & $25.8 / 85.9$ & 100.2 & 5.1 \\
\hline 7 & Tannic acid & 6.30 & 0.9955 & Neg & $f(x)=30233+90.3 x$ & 0.9075 & $100-4000$ & $10.2 / 34.2$ & 97.8 & 5.1 \\
\hline 8 & tr- caffeic acid & 7.11 & 0.9942 & $\mathrm{Neg}$ & $f(x)=83958+1585.2 x$ & 1.0080 & $25-1000$ & $4.4 / 14.7$ & 98.6 & 5.2 \\
\hline 9 & Vanillin & 8.57 & 0.9995 & Neg & $f(x)=-575+44.5 x$ & 0.4094 & $250-10000$ & $10.1 / 33.7$ & 99.2 & 4.9 \\
\hline 10 & p-Coumaric acid & 9.17 & 0.9909 & Neg & $f(x)=27064+73.5 x$ & 1.1358 & $100-4000$ & $15.2 / 50.8$ & 98.4 & 5.1 \\
\hline 11 & Rosmarinic acid & 9.19 & 0.9992 & Neg & $f(x)=-1150+18.0 x$ & 0.5220 & $250-10000$ & $10.4 / 34.8$ & 101.7 & 4.9 \\
\hline 12 & Rutin & 9.67 & 0.9971 & Neg & $\mathrm{f}(\mathrm{x})=3842+51.9 \mathrm{x}$ & 0.8146 & $250-10000$ & $17.0 / 56.6$ & 102.2 & 5.0 \\
\hline 13 & Hesperidin & 9.69 & 0.9973 & $\mathrm{Poz}$ & $f(x)=105641+195.8 x$ & 0.1363 & $250-10000$ & $21.6 / 71.9$ & 100.2 & 4.9 \\
\hline 14 & Hyperoside & 9.96 & 0.9549 & Neg & $f(x)=827+1.0 x$ & 0.2135 & $100-4000$ & $12.4 / 41.4$ & 98.5 & 4.9 \\
\hline 15 & 4-OH Benzoic acid & 11.38 & 0.9925 & Neg & $f(x)=5428+635.0 x$ & 1.4013 & $25-1000$ & $3.0 / 10.0$ & 106.2 & 5.2 \\
\hline 16 & Salicylic acid & 11.39 & 0.9904 & Neg & $f(x)=72571+915.2 x$ & 0.6619 & $25-1000$ & $4 / 13.3$ & 106.2 & 5.0 \\
\hline 17 & Myricetin & 11.42 & 0.9991 & Neg & $f(x)=5415+54.3 x$ & 2.8247 & $100-4000$ & $9.9 / 32.9$ & 106.0 & 5.9 \\
\hline 18 & Fisetin & 12.10 & 0.9988 & Neg & $f(x)=34409+331.9 x$ & 2.4262 & $100-4000$ & $10.7 / 35.6$ & 96.9 & 5.5 \\
\hline 19 & Coumarin & 12.18 & 0.9924 & $\mathrm{Poz}$ & $f(x)=34370+236.6 x$ & 0.4203 & $100-4000$ & $9.1 / 30.4$ & 104.4 & 4.9 \\
\hline 20 & Quercetin & 13.93 & 0.9995 & Neg & $f(x)=1693+206.1 x$ & 4.3149 & $25-1000$ & $2.0 / 6.8$ & 98.9 & 7.1 \\
\hline 21 & Naringenin & 14.15 & 0.9956 & Neg & $f(x)=39056+1100.6 x$ & 2.0200 & $25-1000$ & $2.6 / 8.8$ & 97.0 & 5.5 \\
\hline 22 & Hesperetin & 14.80 & 0.9961 & $\mathrm{Neg}$ & $f(x)=6545+160.3 x$ & 1.0164 & $25-1000$ & $3.3 / 11.0$ & 102.4 & 5.3 \\
\hline 23 & Luteolin & 14.48 & 0.9992 & Neg & $f(x)=3057+111.5 x$ & 3.9487 & $25-1000$ & $5.8 / 19.4$ & 105.4 & 6.9 \\
\hline 24 & Kaempferol & 14.85 & 0.9917 & Neg & $f(x)=571+21.0 x$ & 0.5885 & $25-1000$ & $2.0 / 6.6$ & 99.1 & 5.2 \\
\hline 25 & Apigenin & 16.73 & 0.9954 & $\mathrm{Neg}$ & $(x)=18526+543.8 x$ & 0.6782 & $25-1000$ & $0.1 / 0.3$ & 98.9 & 5.3 \\
\hline 26 & Rhamnetin & 18.41 & 0.9994 & Neg & $f(x)=632+110.1 x$ & 2.5678 & $25-1000$ & $0.2 / 0.7$ & 100.8 & 6.1 \\
\hline 27 & Chrysin & 20.60 & 0.9965 & $\mathrm{Neg}$ & $f(x)=23532+698.8 x$ & 1.5530 & $25-1000$ & $0.05 / 0.17$ & 102.2 & 5.3 \\
\hline
\end{tabular}

${ }^{a}$ RT: retention time; ${ }^{b}{ }^{2}$ : coefficient of determination; ${ }^{\mathrm{c}}$ Ion. Mode: Ionization mode of the analytes; ${ }^{\mathrm{d}} \mathrm{RSD}$ : relative standard deviation; ${ }^{\mathrm{e}} \mathrm{LOD} / \mathrm{LOQ}$ ( $\mu \mathrm{g} / \mathrm{L}$ ): limit of detection/limit of quantification; ${ }^{\mathrm{f}} \mathrm{U}(\%)$ : percent relative uncertainty at $95 \%$ confidence level $(\mathrm{k}=2)$. Neg: negative mode, Poz: positive mode.

the results indicated that phenolic acids were among the most abundant polyphenols detected in all plant parts including quinic, malic, chlorogenic, protocatechuic, $p$-hydroxybenzoic, $p$-coumaric, tr-aconitic, gallic and tannic acids, with quinic acid being equally predominant in both methanol and water leaflets extracts.

As shown in Table 2, a high content of quinic acid identified in leaflets was almost equal to 2.5 times of that found in rachis (37690 \pm 1809 against $13198 \pm 634 \mu \mathrm{g} \mathrm{g}^{-1}$ extract) respectively. In this context, it could be said that $C$. humilis is a good source of quinic acid. Many studies in the literature showed that quinic acid has a potent broad spectrum antioxidant (Pero et al., 2009), hepatoprotective (Xiang et al., 2001) and can be used to combat prostate cancer (Inbathamizh \& Padmini, 2013).

Furthermore, malic acid was the second most prevalent compound after quinic acid in leaflets and fruits. However, in rachis, it was the major organic acid with higher concentration in methanol extract (RM and RW contained $21747 \pm 1153$ against $17614 \pm 933 \mu \mathrm{g} \mathrm{g}^{-1}$ of malic acid, respectively).

Previous work has already demonstrated in other Arecaceae that malic acid was identified as the major compound in Phonix canariensis (Al-Farsi et al., 2005), this organic acid was thought to play an important role in cardioprotective properties (Khazanov et al., 2008).

Methanol showed the highest extraction capacity for chlorogenic acid which took the third place after quinic and malic acid in all extracts. Its presence was dominant in leaflets and rachis. Previous studies have shown that chlorogenic acid blocked chemically induced carcinogens in the large intestine (Mori et al., 1986).

In addition, protocatechuic acid was quantified in all Chamaerops extracts. However, in water solvents approximately equal amounts of protocatechuic acid was obtained (with $33 \pm 2 \mu^{\mathrm{g} \mathrm{g}^{-1}}$ in LW as high concentration). This value was equal to vanillin found also in LW $\left(33 \pm 2 \mu \mathrm{g} \mathrm{g}^{-1}\right)$, and identified slightly less in LM $\left(22 \pm 1 \mu \mathrm{g} \mathrm{g}^{-1}\right)$. The other reflux extracts contained lower concentrations of that molecule. This aldehyde, contributes to the original natural flavour of vanilla and is a very popular flavouring agent used in large range of foods and as fragrance ingredients (Mitra et al., 2002).

Chamaerops extracts contain also minor amounts of $p$-coumaric, tannic, $p$-hydroxybenzoic, gallic, $t r$-caffeic, $t r$-aconitic and salycilic acids. However, traces of rosmarinic acid were found only in few Chamaerops extracts. 
Bouhafsoun et al.

Table 2. Identification and quantification of compounds of water and methanol reflux extracts of C. humilis by LC-MS/MS.

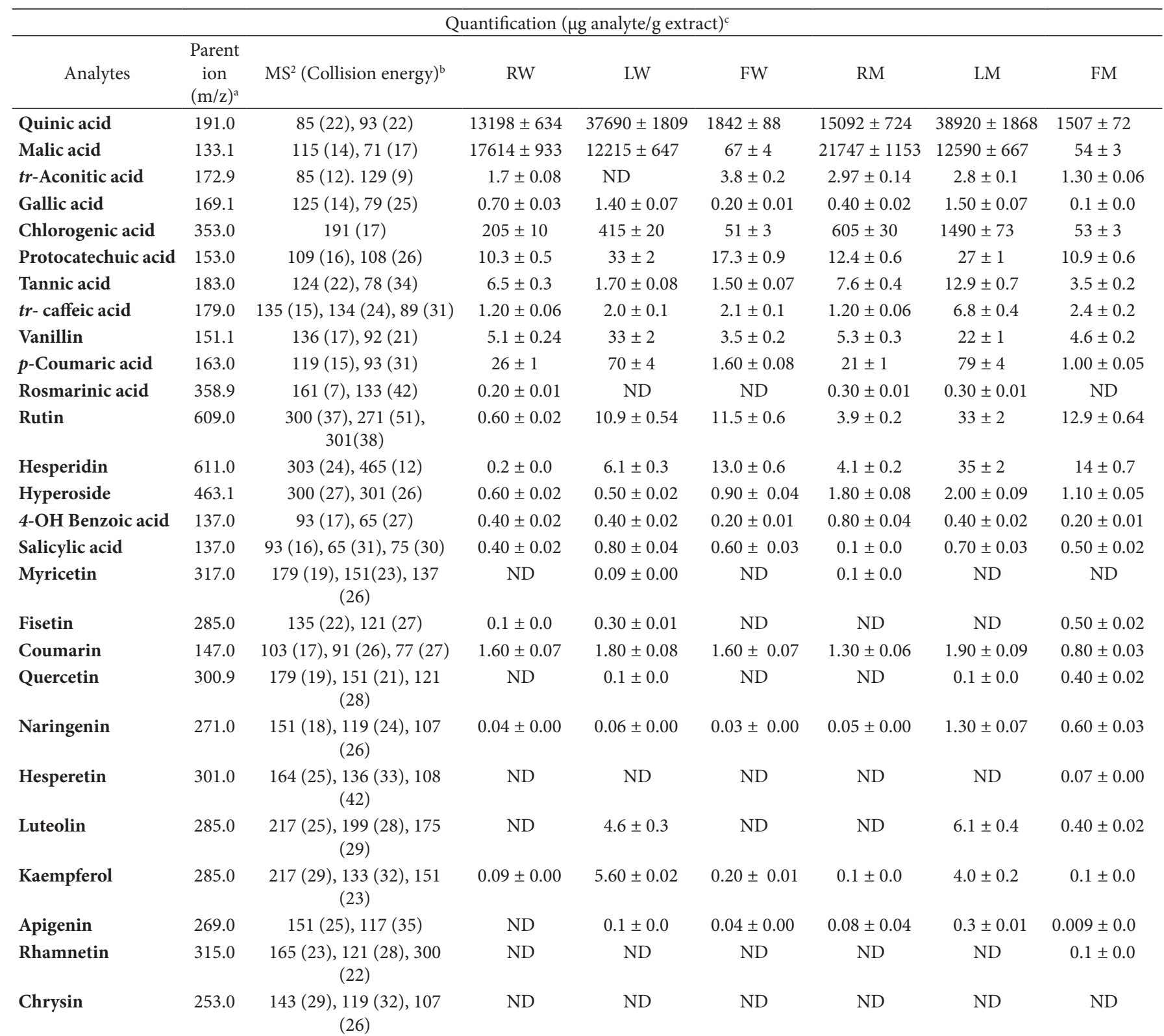

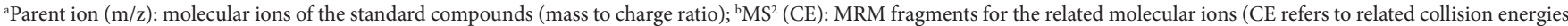
of the fragment ions); ${ }^{c}$ Values in $\mu \mathrm{g} / \mathrm{g}(\mathrm{w} / \mathrm{w})$ of plant methanol extract; N.D.: not detected. RW: Rachis water extract, LW: Leaflets water extract, FW: Fruit water extract, RM: Rachis methanol extract, LM: Leaflets methanol extract, FM: Fruit methanol extract.

Different types of flavonoids such as flavones, flavonols, and flavanones were found in Chamaerops extracts. Flavonoids identified included various flavone- $C$-glycosides of apigenin and luteolin.

Our results showed that heat reflux was a good attractive procedure for the extraction of luteolin in both methanol and water extracts of leaflets. However, it was not identified in rachis and fruits parts.

Flavone $C$-glycosides and tricin were previously identified in C. humilis leaves (Williams et al., 1973; Hirai et al., 1986). These results showed that the rutin and kaempferol were identified in all Chamaerops extracts, a higher content was obtained in methanol extracts of leaflets $\left(33 \pm 2 \mu \mathrm{g} \mathrm{g}^{-1}\right)$, water was extracted three times less rutin $\mathrm{LW}\left(10.9 \pm 0.54 \mu \mathrm{g} \mathrm{g}^{-1}\right)$. In a previous study rutin was identified from the C. humilis leaves (Hirai et al., 1986) and Phoenix dactylifera L. fruits (Hamad et al., 2015).

According to the literature, kaempferol glycosides are widely distributed in the Arecaceae family (Williams et al., 1973).

LC-ESI-MS-MS detected traces of fisetin, rhamnetin and myricitin in only some Chamaerops extracts. The presence of quercetin traces has been present only in methanol extracts. Nonetheless, flavonoid $C$-glycosides were already identified from plants of the Arecaceae family. Flavone $C$-glycosides (84\%), tricin (51\%), luteolin (30\%) and quercetin glycosides (24\%) 


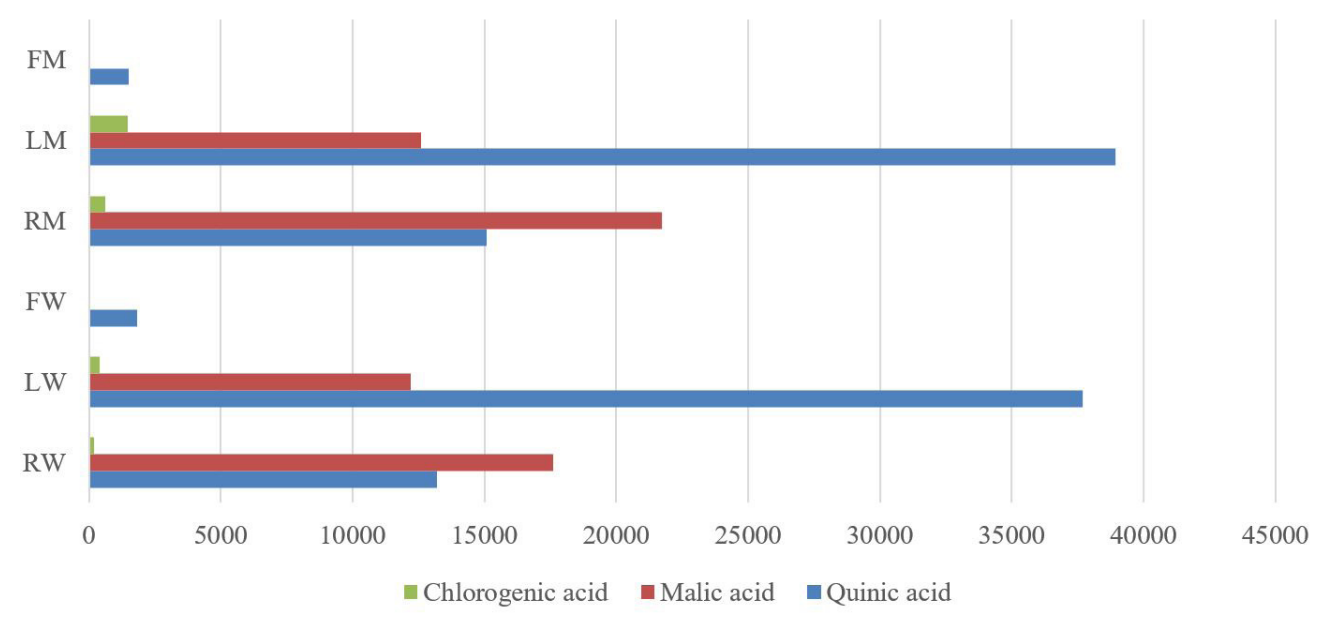

Figure 2. Graph that shows the concentrations ( $\mu$ g analyte/g extract) of chlorogenic, malic and quinic acids in methanol and water extracts of different parts. RW: Rachis water extract, LW: Leaflets water extract, FW: Fruit water extract, RM: Rachis methanol extract, LM: Leaflets methanol extract, FM: Fruit methanol extract.

were found out in the leaves of the 125 species of the Palmae (Williams et al., 1973).

Regarding the flavanone group, naringenin was weakly identified in all Chamaerops extracts. It is important to note that hesperitin was not identified, while its glycoside hesperidin (which is conjugates with rhamnosyl- $\alpha-1,6$-glucose) was found. However, its concentration has decreased about 6 times less in water extracts $\left(35 \pm 2\right.$ and $6.2 \pm 0.3 \mu \mathrm{g} \mathrm{g}^{-1}$ in LM and LW respectively), this reflects the solubility behaviour of hesperidin (Grandi et al., 1994).

Finally, methanol was more effective extraction solvent, which resulted in the coextraction of lots of compounds (Figure 2).

\section{Conclusion}

In the present study, phenolic composition of leaflets, rachis and fruits parts of $C$. humilis var. argentea were identified by using heated reflux extraction and liquid chromatography tandem mass spectrometry (LC-MS/MS) analysis techniques. The LC-MS/MS results revealed that quinic, malic and chlorogenic acids and rutin and hesperidin were the major phenolic compounds in leaflets and fruits extracts. Besides, the methanol extract was detected to be the most efficient solvent to identify phenolic compounds in C. humilis. This approach showed that Chamaerops was a great promising source of different bioactive components, particularly phenolic acids and flavonoids. In vivo studies are required to determine its benefits as potential food ingredients and being agents for protection against various diseases. Therefore, the growing use of Chamaerops in foods was encouraged.

\section{Acknowledgements}

This work is a part of CNEPRU project $\mathrm{N}^{\circ}$ D01N01UN3102 20130030 supported by High Teaching and Scientific Research Ministry www.mesrs.dz and Oran University of Sciences and Technology www.univ-usto.dz. The authors are thankful to Dicle University Science and Technology Research and Application Center (DUBTAM) in Diyarbakir, TURKEY for opening its laboratory facilities.

\section{References}

Al-Farsi, M., Alasalvar, C., Morris, A., Baron, M., \& Shahidi, F. (2005). Compositional and sensory characteristics of three native sun-dried date (Phoenix dactylifera L.) Varieties Grown in Oman. Journal of Agricultural and Food Chemistry, 53(19), 7586-7591. http://dx.doi. org/10.1021/jf050578y. PMid:16159190.

Androutsopoulos, V. P., Papakyriakou, A., Vourloumis, D., Tsatsakis, A. M., \& Spandidos, D. A. (2010). Dietary flavonoids in cancer therapy and prevention: substrates and inhibitors of cytochrome P450 CYP1 enzymes. Pharmacology \& Therapeutics, 126(1), 9-20. http://dx.doi. org/10.1016/j.pharmthera.2010.01.009. PMid:20153368.

Balci, F., \& Özdemir, F. (2016). Influence of shooting period and extraction conditions on bioactive compounds in Turkish green tea. Food Science and Technology (Campinas), 36(4), 737-743. http:// dx.doi.org/10.1590/1678-457x.17016.

Beghalia, M., Ghalem, S., Allali, H., Beloutek, A., \& Marouf, A. (2008). Inhibition of calcium oxalate monohydrate crystal growth using Algerian medicinal plants. Journal of Medicinal Plants Research, 2, 66-70.

Bellakhdar, J., Claisse, R., Fleurentin, J., \& Younos, C. (1991). Repertory of standard herbal drugs in the Moroccan pharmacopoeia. Journal of Ethnopharmacology, 35(2), 123-143. http://dx.doi.org/10.1016/03788741(91)90064-K. PMid:1809818.

Benahmed-Bouhafsoun, A., Djied, S., Mouzaz, F., \& Kaid-Harche, M. (2013). Phytochemical composition and in vitro antioxidant activity of Chamaerops humilis L. extracts. International Journal of Pharmacy and Pharmaceutical Sciences, 5, 741-744.

Bnouham, M., Mekhfi, H., Legssyer, A., \& Ziyyat, A. (2002). Ethnopharmacology Forum Medicinal plants used in the treatment of diabetes in Morocco. International Journal of Diabetes and Metabolism, 10, 33-50.

Ertas, A., Yilmaz, M. A., \& Firat, M. (2015). Chemical profile by LCMS/MS, GC/MS and antioxidant activities of the essential oils and crude extracts of two Euphorbia species. Natural Product Research, 29(6), 529-534. http://dx.doi.org/10.1080/14786419.2014.954113. PMid:25184782.

Ertas, A., Yilmaz, M. A., Boga, M., Hasimi, N., Yesil, Y., Goren, A. C., Temel, H., \& Topcu, G. (2016). Chemical profile and biological activities of two edible plants: chemical investigation and quantitative 
analysis using liquid chromatography tandem mass spectrometry and gas chromatography mass spectrometry. International Journal of Food Properties, 19(1), 124-138. http://dx.doi.org/10.1080/1094 2912.2015.1020437.

Gaamoussi, F., Israili, Z. H., \& Lyoussi, B. (2010). Hypoglycemic and hypolipidemic effects of an aquous extract of Chamaerops humilis leaves in obese, hyperglycemic and hyperlipidemic Meriones shawi rats. Pakistan Journal of Pharmaceutical Sciences, 23(2), 212-219. PMid:20363702.

Grandi, R., Trifiro, A., Gherardi, S., Calza, M., \& Saccani, G. (1994). Characterization of lemon juice on the basis of flavonoid content. Fruit Processing, 11, 355-359.

Hamad, I., Abd Elgawad, H., Al Jaouni, S., Zinta, G., Asard, H., Hassan, S., Hegab, M., Hagagy, N., \& Selim, S. (2015). Metabolic Analysis of Various Date Palm Fruit (Phoenix dactylifera L.) Cultivars from Saudi Arabia to Assess Their Nutritional Quality. Molecules (Basel, Switzerland), 20(8), 13620-13641. http://dx.doi.org/10.3390/ molecules200813620. PMid:26225946.

Hasnaoui, O., Benali, O., Bouazza, M., \& Benmehdi, H. (2013). Ethnobotanical approaches and phytochemical analysis of Chamaerops humilis L. (Arecaceae) in the area of Tlemcen (western Algeria). Research Journal of Pharmaceutical, Biological and Chemical Sciences, 4(2), 910-918.

Hasnaoui, O., Bouazza, M., Benali, O., \& Thinon, M. (2011). Ethno botanic study of Chamaerops humilis L. Var. argentea Andre (Arecaceae) in Western Algeria. Agricultural Journal, 6(1), 1-6. http://dx.doi.org/10.3923/aj.2011.1.6.

Hirai, Y., Sanada, S., Ida, Y., \& Shoji, J. (1986). Studies on the Constituents of Palmae Plants. III. The Constituents of Chamaerops humilis L. and Trachycarpus wagnerianus BECC. Chemical \& Pharmaceutical Bulletin, 34(1), 82-87. http://dx.doi.org/10.1248/cpb.34.82.

Inbathamizh, L., \& Padmini, E. (2013). Quinic acid as a potent drug candidate for prostate cancer - a comparative pharmacokinetic approach. Asian Journal of Pharmaceutical and Clinical Research, 6, 106-112.

Khazanov, V. A., Kiseliova, A. A., Vasiliev, K. Y., \& Chernyschova, G. A. (2008). Cardioprotective effects of trimetazidine and a combination of succinic and malic acids in acute myocardial ischemia. Bulletin of Experimental Biology and Medicine, 146(2), 218-222. http://dx.doi. org/10.1007/s10517-008-0259-3. PMid:19145322.

Khoudali, S., Benmessaoudleft, D., Essaqui, A., Zertoubi, M., Azzi, M., \& Benaissa, M. (2014). Study of antioxidant activity and anticorrosion action of the methanol extract of dwarf palm leaves (Chamaerops humilis L.) from Morocco. Journal of Materials and Environmental Science, 5(3), 887-898.
Ma, G. Z., Wang, C. M., Li, L., Ding, N., \& Gao, X. L. (2015). Effect of Pomegranate Peel Polyphenols on Human Prostate Cancer PC-3 cells in vivo. Food Science and Biotechnology, 24(5), 1887-1892. http://dx.doi.org/10.1007/s10068-015-0247-0.

Mitra, A., Mayer, M., Mellon, F., Michael, A., Narbad, A., Parr, A., Waldron, K., \& Walton, N. (2002). 4-Hydroxycinnamoyl-CoA hydratase/lyase, an enzyme of phenylpropanoid cleavage from Pseudomonas, causes formation of $\mathrm{C}(6)-\mathrm{C}(1)$ acid and alcohol glucose conjugates when expressed in hairy roots of Datura stramonium L. Planta, 215(1), 79-89. http://dx.doi.org/10.1007/s00425-001-0712-2. PMid:12012244.

Mori, H., Tanaka, T., Shima, H., Kuniyasu, T., \& Takahashi, M. (1986). Inhibitory effect of chlorogenic acid on methylazoxymethanol acetateinduced carcinogenesis in large intestine and liver of Hamsters. Cancer Letters, 30(1), 49-54. http://dx.doi.org/10.1016/03043835(86)90131-X. PMid:3943079.

Park, J., Kim, S. H., \& Kim, T. S. (2006). Inhibition of interleukin-4 production in activated $\mathrm{T}$ cells via down-regulation of NF-AT DNA binding activity by apigenin, a flavonoid present in dietary plants. Immunology Letters, 103(2), 108-114. http://dx.doi.org/10.1016/j. imlet.2005.10.002. PMid:16280168.

Pero, R., Lund, H., \& Leanderson, T. (2009). Antioxidant metabolism induced by quinic acid: increased urinary excretion of tryptophan and nicotinamide. Phytotherapy Research, 23(3), 335-346. http:// dx.doi.org/10.1002/ptr.2628. PMid:18844285.

Rahimi, R., Ghiasi, S., Azimi, H., Fakhari, S., \& Abdollahi, M. (2010). A review of the herbal phosphodiesterase inhibitors: Future perspective of new drugs. Cytokine, 49(2), 123-129. http://dx.doi.org/10.1016/j. cyto.2009.11.005. PMid:20005737.

Shirley, B. W. (1996). Flavonoid biosynthesis: «new » functions for an " old " pathway. Trends in Plant Science, 31, 377-382.

Siahpoosh, A., Asili, J., \& Sarhangi, B. (2016). Antioxidative and Free Radical Scavenging Activities of Some Extracts from Ripe Fruits of Phonix dactylifera L. International Journal of Pharmacognosy and Phytochemical Research, 8(10), 1735-1741.

Williams, C. A., Harborne, J. B., \& Clifford, H. T. (1973). Negatively charged flavones and tricin as chemosystematic markers in the Palmae. Phytochemistry, 12(10), 2417-2430. http://dx.doi.org/10.1016/00319422(73)80449-2.

Xiang, T., Xiong, Q. B., Ketut, A. I., Tezuka, Y., Nagaoka, T., Wu, L. J., \& Kadota, S. (2001). Studies on the hepatocyte protective activity and the structure-activity relationships of quinic acid and caffeic acid derivatives from the flower buds of Lonicera bournei. Planta Medica, 67(4), 322-325. http://dx.doi.org/10.1055/s-2001-14337. PMid:11458447. 